\title{
Post Stroke Pain: Identification, Assessment, and Therapy
}

\author{
Rebecca A. Harrison Thalia S. Field \\ Division of Neurology, University of British Columbia, Vancouver, B.C., Canada
}

\section{Key Words}

Stroke · Pain - Complications · Therapy - Quality of life ·

Spasticity $\cdot$ Central post-stroke pain $\cdot$ Complex regional pain syndrome $\cdot$ Shoulder subluxation

\begin{abstract}
Background: Pain is a common complication after stroke and is associated with the presence of depression, cognitive dysfunction, and impaired quality of life. It remains underdiagnosed and undertreated, despite evidence that effective treatment of pain may improve function and quality of life. Summary: We provide an overview of the means for clinical assessment and risk factors for the development of poststroke pain, then review the newest available literature regarding the commonest post-stroke pain syndromes, including central post-stroke pain, complex regional pain syndrome, musculoskeletal pain including shoulder subluxation, spasticity-related pain, and post-stroke headache, as well as the available epidemiology and current treatment options. Key Messages: In the best interests of optimizing quality of life and function after stroke, clinicians should be aware of pain as a common complication after stroke, identify those patients at highest risk, directly inquire as to the presence and characteristics of pain, and should be aware of the options for treatment for the various pain syndromes.
\end{abstract}

(c) 2015 S. Karger AG, Basel
(C) 2015 S. Karger AG, Basel

1015-9770/15/0394-0190\$39.50/0

\section{Introduction}

Chronic pain syndromes are common after stroke and are found in up to one-half of stroke patients [1]. As many as $70 \%$ of affected patients experience pain on a daily basis [2].

The reported prevalence of post-stroke pain (PSP) varies, reflecting differences in study design, definitions of pain types, and sampled cohorts (table 1). Still, there is a general consensus that PSP is an underreported phenomenon. PSP often goes undisclosed by patients unless active inquiry is made by the physician [3]. Even when identified, PSP may not be sufficiently treated. In one retrospective study, it was found that two-thirds of those with central pain had inadequate pain treatment, or were prescribed no treatment at all [4].

Various non-motor complications of stroke commonly co-occur in those with PSP (table 2). Patients with pain experience greater cognitive and functional decline [5], lower quality of life [1], fatigue [6], and depression [7]. PSP is a predictor of suicidality after stroke [8]. Pain severity correlates with severity of cognitive impairment and depression [9]. The relationships between these variables continue to be explored [10-13].

Multiple factors contribute to post-stroke pain, including central and peripheral mechanisms, psychologi-

\section{KARGER 125}

E-Mail karger@karger.com www.karger.com/ced
Thalia S. Field

S169-2211 Wesbrook Mall

Vancouver BC V6T 2B5 (Canada)

E-Mail thalia.field@ubc.ca 
Table 1. Prevalence of post-stroke pain syndromes

\begin{tabular}{|c|c|c|c|c|}
\hline Study & Design & Prevalence, $\mathrm{n}$ & $\begin{array}{l}\text { Mean time from infarct to pain } \\
\text { syndrome }\end{array}$ & Additional information \\
\hline $\begin{array}{l}\text { Langhorne, } \\
2000[3]\end{array}$ & $\begin{array}{l}\text { Prospective study recruiting } \\
\text { patients at } 3 \text { centers with } 30 \\
\text { months follow-up }(n=311)\end{array}$ & $\begin{array}{l}43 \%(\mathrm{n}=134 / 311) \\
\text { over follow-up period } \\
\text { (incidence) }\end{array}$ & N/A & $\begin{array}{l}9 \% \text { had shoulder pain } \\
34 \% \text { had other types of pain over } \\
\text { follow-up period }\end{array}$ \\
\hline $\begin{array}{l}\text { Widar, } \\
2002[4]\end{array}$ & $\begin{array}{l}\text { Inpatient registry at University } \\
\text { Hospital } \\
\text { Retrospective analysis with data } \\
\text { gathered at } 2 \text { years post-stroke } \\
\mathrm{n}=972 \text { patients on register, } \\
(\mathrm{n}=43) \text { included in study }\end{array}$ & $\begin{array}{l}\text { No overall prevalence } \\
\text { measured }(\mathrm{n}=43)\end{array}$ & $\begin{array}{l}65 \% \text { developed pain syndrome } \\
\text { between } 1-6 \text { months post-stroke } \\
\text { Syndromes developed at different } \\
\text { times: < } 1 \text { week: } 28 \% \\
1 \text { week-1 month: } 23 \% \\
2-6 \text { months: } 44 \% \\
20-27 \text { months: } 5 \%\end{array}$ & $\begin{array}{l}\text { Types of pain syndromes: } \\
\text { CPSP: } 35 \%(n=15 / 43) \\
\text { Nociceptive pain: } 42 \%(18 / 43) \\
\text { Tension-type headache: } 23 \%(n=10 / 43)\end{array}$ \\
\hline $\begin{array}{l}\text { Kong, } \\
2004[134]\end{array}$ & $\begin{array}{l}\text { Cross-sectional survey of an } \\
\text { outpatient clinic at a tertiary } \\
\text { rehab centre } \\
\text { Screened for participants over a } \\
3 \text { months period }(\mathrm{n}=107)\end{array}$ & $42 \%(\mathrm{n}=45 / 107)$ & N/A & $\begin{array}{l}71 \% \text { of pain was MSK-type }(\mathrm{n}=32) ; 29 \% \\
\text { central }(\mathrm{n}=13) \\
\text { Pain was associated with a shorter } \\
\text { amount of time post-stroke (mean } 15.9 \\
\text { months versus pain-free patients in the } \\
\text { registry who were mean } 22.8 \text { months } \\
\text { post-stroke) }\end{array}$ \\
\hline $\begin{array}{l}\text { Jonsson, } \\
2006[9]\end{array}$ & $\begin{array}{l}\text { Population-based registry } \\
\text { Prospective, assessed at } 4(\mathrm{n}= \\
\text { 329) and } 16 \text { months }(\mathrm{n}=297) \\
\text { post-stroke by interview }\end{array}$ & $\begin{array}{l}4 \text { months: } 32 \% \text { of } 329 \\
\text { had moderate to } \\
\text { severe pain, } 7 \% \text { had } \\
\text { mild pain } \\
\text { At } 16 \text { months: } 21 \% \text { of } \\
297 \text { had moderate to } \\
\text { severe pain, } 4 \% \text { had } \\
\text { mild pain }\end{array}$ & $\begin{array}{l}\text { Pain onset at } 4 \text { months visit: before } \\
\text { stroke } 38 \%, 0-2 \text { weeks post-stroke } \\
31 \%, 2 \text { weeks }-2 \text { months post-stroke } \\
14 \%,>2 \text { months post-stroke } 17 \% \\
\text { Pain onset at } 16 \text { month visit: before } \\
\text { stroke } 40 \%, 0-2 \text { weeks after stroke } \\
26 \%, 2 \text { weeks- } 2 \text { months after stroke } \\
5 \%,>2 \text { months after stroke } 29 \%\end{array}$ & $\begin{array}{l}\text { Visual analogue scales (VAS) used to } \\
\text { measure pain } \\
\text { VAS significantly worse for those with } \\
\text { moderate to severe pain at } 16 \text { months as } \\
\text { opposed to those at } 4 \text { months } \\
\text { Self perceived cause of pain at } 16 \text { months } \\
\text { was stroke in } 36 \%\end{array}$ \\
\hline $\begin{array}{l}\text { Lundström, } \\
2009[7]\end{array}$ & $\begin{array}{l}\text { Cross-sectional survey performed } \\
\text { on patients part of the Swedish } \\
\text { National Quality Register for } \\
\text { Stroke Care }(\mathrm{n}=147)\end{array}$ & $49 \%(\mathrm{n}=68 / 147)$ & N/A & $\begin{array}{l}21 \% \text { of patients had pain related to } \\
\text { stroke } \\
9 \% \text { total related to shoulder pain } \\
4 \% \text { central post-stroke pain } \\
11 \% \text { total hip/leg/foot pain }\end{array}$ \\
\hline $\begin{array}{l}\text { O’Donnell, } \\
2013 \text { [5] }\end{array}$ & $\begin{array}{l}\text { Standard questionnaire } \\
\text { administered as part of a } \\
\text { randomized control trial. } \\
\text { Patients enrolled } 90-120 \text { days } \\
\text { after ischemic stroke }(\mathrm{n}=15,754)\end{array}$ & $\begin{array}{l}10.6 \% \\
(\mathrm{n}=1,665 / 15,754)\end{array}$ & $\begin{array}{l}\text { Questionnaire administered at } \\
\text { penultimate follow-up visit }\end{array}$ & $\begin{array}{l}\text { Of those with identifiable sources/ } \\
\text { etiologies, } 2.7 \% \text { had CPSP, } 1.5 \% \text { with } \\
\text { peripheral neuropathy, } 1.3 \% \text { with pain } \\
\text { attributable to spasticity }\end{array}$ \\
\hline
\end{tabular}

MSK = Musculoskeletal; CPSP = central post-stroke pain.

cal factors, and autonomic input. There are multiple treatment approaches that attempt to target these contributors (fig. 1). While the relationship between pain and these variables is complex, evidence from the non-stroke literature suggests that treatment of pain is associated with improvement of cognition and quality of life. Treatment of pain with opioids and amitriptyline has been shown to reverse pain-related cognitive impairment [14, 15]. Similarly, studies of osteoarthritis and post-herpetic neuralgia have shown that improved pain control, regardless of modality, is associated with improved perceived quality of life [16-19].

Currently, post-stroke pain is under-recognized and under-treated. Ensuring that clinicians are familiar with 
Fig. 1. Psychological, central, peripheral, and autonomic factors contributing synergistically to post-stroke pain and associated targeted therapeutic strategies (adapted from Gierthmulen et al. [111]). CBT = Cognitive-behavioral therapy; OT $=$ Occupational therapy; $\mathrm{PT}=$ physiotherapy.

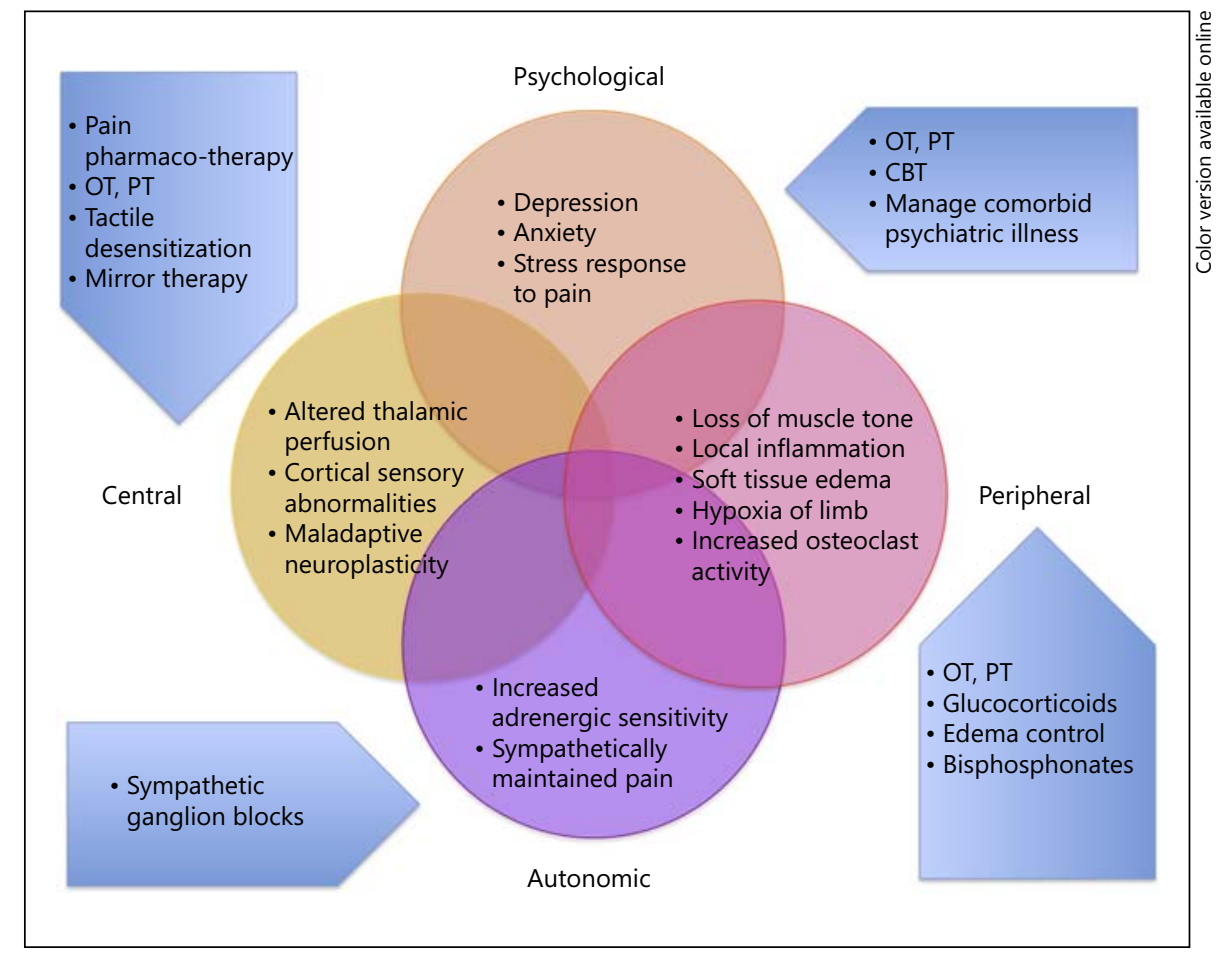

Table 2. Non-motor complications of PSP

Complications Associated with Post-Stroke Pain
Cognitive decline
Functional decline
Fatigue
Depression
Suicidality
Lower quality of life

Table 3. Reported risk factors for the development of PSP

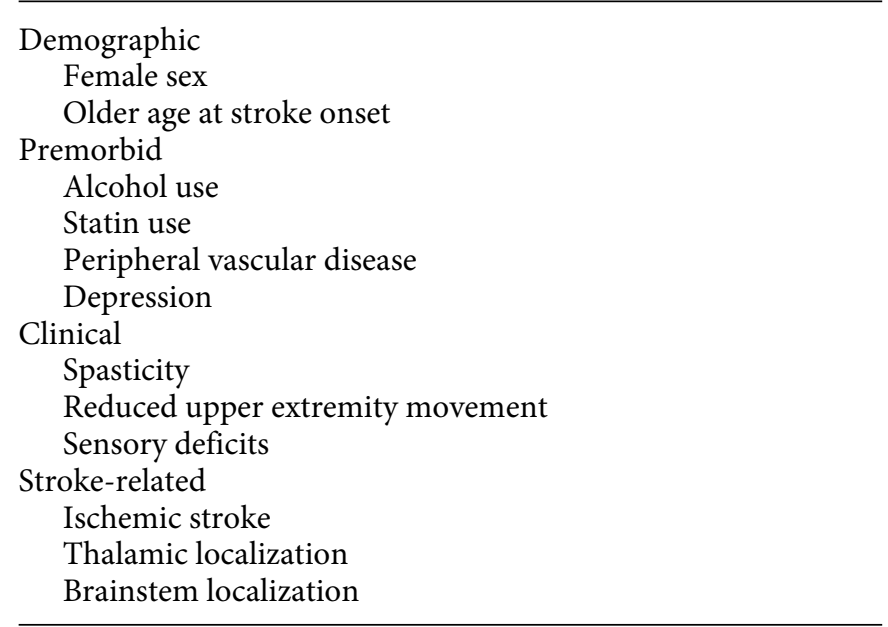

the pain syndromes after stroke, their identification, and their treatment can have a significant impact on pain outcomes, as well as on other variables that impact quality of life. Prognosis with regards to pain outcomes is improved when pain is treated early and aggressively [20]. Health providers should routinely assess for this common and important complication post-stroke, and have an understanding of its presentation and treatment to manage patients effectively. Patients are often inadequately educated about post-stroke pain, and may stop treatment too early if they are not properly informed [4].

\section{Risk Factors}

Various patient characteristics have been identified as independent risk factors for the development of PSP [5] (table 3). Incidence of PSP increases with age at stroke onset [21]. Clinical features associated with the development of PSP include increased muscle tone, reduced upper extremity movement, and sensory deficits [21]. Ischemic stroke is more frequently associated with pain than hemorrhagic stroke [2]. Stroke localization also has a role, with an overrepresentation of PSP after thalamic and brainstem strokes [2]. 


\section{Identification of PSP}

Challenges in Identifying Post-Stroke Pain

Several factors present challenges in the identification, assessment, and characterization of PSP, including the subjective nature of symptoms and patient-related factors, such as reluctance to disclose symptoms, language deficits, and neglect syndromes. There is significant variability in how pain is assessed for research purposes, with self-reported questionnaires, pain scales, and clinical assessment providing most of the data. Actively inquiring about pain is essential, as many patients do not volunteer these symptoms, particularly the elderly $[22,23]$.

The particular clinical deficits caused by strokes are associated with difficulties in reporting pain [24]. Although there are several rating scales for pain, no specific pain scale has been devised for the assessment of poststroke pain. Options include visual analogue scales, faces pain scales, numeric rating scales, and verbal descriptor scales. In spite of these varied options, stroke patients are less likely than age-matched controls to be able to complete rating scales [25]. It is important to tailor the scale to the individual's deficits. For instance, the use of a faces pain scale has been found to be more reliable in left than right hemispheric strokes [26]. There is likely no single scale effective for all stroke patients given the heterogeneity of neurologic deficits in this population [26].

\section{Common Post-Stroke Pain Subtypes}

PSP occurs through both neuropathic and nociceptive mechanisms. Efforts to standardize descriptive terms for pain led to a publication by the International Association for the Study of Pain of pain terms and their definitions [27]. These are commonly used in studies of PSP to define pain subtypes [28-32]. The commonest types of PSP are central post-stroke pain (CPSP), pain secondary to spasticity, shoulder pain, complex regional pain syndrome (CRPS), and headache $[5,33]$. Many patients report more than one pain subtype [2], with common combinations being CPSP and spasticity, or CPSP and shoulder pain [5]. By definition, CRPS has features of neuropathic pain, and as such, these syndromes co-occur as well.

\section{Central PSP}

Prevalence, Risk Factors, and Clinical Characteristics

CPSP is a common pain syndrome after stroke, estimated to account for over one-third of cases of poststroke pain [4]. Latency to onset is variable. Most commonly, it develops within 3 to 6 months of stroke [34], though it may occur within a month after stroke [35]. Symptom onset is often gradual, coinciding with the improvement of perceived sensory loss and the appearance of dysesthesia [35]. The pain is frequently severe and unrelenting, with pain-free episodes not exceeding a few hours [35]. Risk factors for development of CPSP include young age, previous depression, current smoking and increased baseline stroke severity $[5,36]$. Of note, a recent large cohort study confirmed that young stroke patients are twice as likely to develop CPSP (Helsinki Stroke Study) [36].

In general, there are thought to be three types of pain components with CPSP: (1) a constant pain, (2) a spontaneous intermittent component, and (3) hyperalgesia/ allodynia [37]. The clinical features, diagnostic criteria and proposed pathophysiology and treatment of CPSP have been discussed in detail previously [31].

Localization and Proposed Pathophysiology

Thalamic lesions are commonly associated with pain, with Dejerine-Roussy syndrome being the best characterized CPSP syndrome. This syndrome accounts for approximately one-third of the cases of CPSP [35] and is characterized by severe and paroxysmal pain, accompanied by allodynia and hyperalgesia [38]. Lesions beyond the thalamus at any level of the neuroaxis, however, can produce neuropathic pain, particularly with the involvement of the spinothalamic tracts. Lateral medullary syndrome is the commonest brainstem syndrome associated with CPSP [29]. Approximately $80 \%$ of lesions causing CPSP are hemispheric [37]. Cortical strokes causing CPSP often involve the parietal lobe and possibly the underlying white matter [39]. Strokes affecting the right hemisphere are more commonly associated with pain, for both thalamic and non-thalamic strokes [35]. One explanation suggests the right hemisphere is more adept at monitoring the somatic state, and thus at pain processing; this leads to pain conditions being more intense in the left hemibody [40]. However, this lateralization is not consistently reproduced [41]. CPSP has also demonstrated a strong association with small vessel infarcts [5], likely because of the common association of this stroke mechanism with thalamic or pontine lesions $[5,42]$.

Identification in the Clinical Setting and Therapy

The presentation of CPSP is variable. Certain clinical characteristics, discussed in detail in previous reviews, can aid in its identification [31] (table 4). Adjectives such as lacerating, aching, burning, freezing, and squeezing are commonly used by patients [28]. Pain is often constant 
Table 4. Clinical Features for identification of CPSP

Verbal Descriptors Used: lacerating, aching, burning, freezing, squeezing

Spontaneous dysesthesia

Allodynia to touch and mild temperatures

Variable pain quality

Abnormal sensitivity to pinprick and high temperatures

Raised thresholds for perception of touch and two-point discrimination

[28]. Based on these findings, diagnostic criteria for CPSP have been proposed [6].

CPSP is challenging to treat, and often involves a trialand-error process with multiple different therapies. Various pharmacologic agents have been found to be effective in these patients, including tricyclic antidepressants, selective serotonin reuptake inhibitors, and antiepileptics, including lamotrigine, gabapentin, and pregabalin, and have been discussed in previous reviews $[4,6]$. Intravenous lidocaine [43] and ketamine [44] have also been for acute relief in CPSP, but reports are limited to small case series. Currently, there is no evidence for pharmacologic prophylaxis for pain in stroke patients [45].

Newer studies have looked at the utility of methylprednisolone and levetiracetam in the treatment of CPSP. One small retrospective series found a reduction in pain scores and as-needed pain medications with a tapering oral course of methylprednisolone, though this has not been tested prospectively or in a randomized fashion [46]. Although other anti-seizure medications are helpful in CPSP, studies of levetiracetam have been disappointing. A 2013 Cochrane review found it ineffective for neuropathic pain [8], and a recent double-blind randomized control trial found it ineffective for CPSP specifically [9].

Neurostimulatory therapy has also been evaluated in central pain syndromes, including refractory cases of CPSP. The effectiveness of motor cortex stimulation was estimated to be around 50\% in a systematic review [47], with effectiveness up to $77 \%$ when somatosensory evoked potentials were used to confirm stimulating electrode placement [48]. These success rates are lower than in patients with spinal cord injury and peripheral neuropathic pain $[47,49]$. Deep brain stimulation has been utilized with electrodes being placed in the somatosensory thalamus and periventricular gray area; however, results have been disappointing for CPSP [50]. Noninvasive techniques for treatment of CPSP have also been explored. Repetitive transcranial magnetic stimulation (rTMS), with repetitive daily stimulation of the motor cortex, has been shown to be effective in CPSP and may provide sustained pain relief [50]. One small case series of caloric stimulation in patients with CPSP found that this simple method provided lasting symptomatic relief [51].

\section{Spasticity-Related Pain}

Prevalence, Risk Factors and Clinical Characteristics

Spasticity is an abnormal pattern of muscle activation with externally imposed perturbation [52]. It is common after stroke, with nearly one-quarter of patients developing some increase in muscle tone within one week [53]. Spasticity itself can take on various forms. In its simplest form, it is velocity-dependent increased tone. Other features of an upper motor neuron syndrome include spastic dystonia, spastic co-contraction, and exaggerated reflexes [54]. The majority of patients with spasticity after stroke experience pain [21]. A prospective observational study demonstrated a strong association between the development of spasticity and pain, with $72 \%$ of patients with spasticity developing pain, while only $1.5 \%$ of non-spastic patients experienced pain syndromes [53].

\section{Proposed Pathophysiology}

The nature of the relationship between spasticity and pain is not fully understood. There are potential neuropathic and nociceptive mechanisms by which they are related [7]. The neuronal networks that mediate pain and spasticity at the spinal and cerebral levels may overlap, supported by the finding that pain is be reduced by stimulation of cortical motor areas $[50,55]$. Nociceptive pain may be produced by the abnormal loading on muscles and ligaments caused by spasticity [7]. Spasticity can cause changes in rheologic muscle properties, leading to fibrosis, and atrophy [56]. Patients often report pain independent of exacerbations of spasticity, suggesting that the pain may be related to prolonged abnormal muscle contraction [57]. Patients with a higher degree of spasticity have been found to have lower Barthel Index scores, lower quality of life, and more pain [53].

\section{Identification in the Clinical Setting and Therapy}

A thorough clinical assessment is essential in the identification of spasticity. Low Barthel Index Score at day 7, hemiplegia at admission, left-sided weakness, and smoking history have been identified as independent risk factors for the development of spasticity [58]. On physical exam, spasticity is detected by an increased response to passive movement. Other more quantitative scales as well as electromyography have also been used to characterize spasticity, though primarily in the research setting $[52,59]$. 
Pain can be considered an indication for treatment of spasticity using local neuromuscular blockade or pharmacological treatment, but must be weighed against the disadvantage of removing the potential functional benefits of increased muscle tone. In general, the goal of treatment is to reduce reflex activity, thus reducing muscle tone. Mechanical muscle fiber properties may propagate spasticity, and can also be targeted [56]. There is little evidence regarding the treatment of spasticity specifically after stroke [60]; much of the evidence is derived from the literature on other neurologic conditions, such as multiple sclerosis and cerebral palsy and is well summarized elsewhere [61-66].

\section{Musculoskeletal Pain: Glenohumeral Subluxation and} Contractures

Prevalence, Risk Factors and Clinical Characteristics

Shoulder pain is a common nociceptive pain syndrome post-stroke [67]. Musculoskeletal shoulder pain can be divided into two main types: shoulder subluxation (inferior glenohumeral joint displacement) and contractures.

It is reported that hemiplegic shoulder pain is prevalent in $16-72 \%$ of stroke patients [67-71]. Prevalence is commonly estimated between one-quarter and one-half of stroke patients $[67,71,72]$. Pain onset is often within 3 weeks of the stroke [71]. Risk factors associated with the development of shoulder pain include upper extremity weakness and stroke severity $[69,73]$. Other high-risk features for shoulder pain include sensory abnormalities [69], an abnormal rheumatologic exam [69], spasticity [74], right hemispheric lesions [75] and a low Barthel Index Score [68]. In comparing groups of patients with and without shoulder pain in a rehabilitation facility, those without shoulder pain were significantly more likely to be functionally independent [72].

\section{Pathophysiology}

The development of shoulder pain is likely multifactorial and can involve glenohumeral subluxation, impingement, rotator cuff tears, bicipital tendinitis, and CRPS. The shoulder joint is unique compared to most joints in the body, as it is loosely constrained by a thin articular capsule, relying on muscles and ligaments for stability (fig. 2). Weakness can thus lead to instability and immobility of the glenohumeral joint. Glenohumeral subluxation, can result from the weakness of these surrounding muscles. Subluxation can occur immediately after stroke, when the upper extremity has flaccid tone and is most vulnerable to instability [76]. However, pain most often becomes apparent when spasticity develops [69]. The evolution of subluxation is associated with the development of shoulder pain, and reduced functional outcomes of the affected upper extremity [77]. Potential complications of subluxation also include CRPS [18] and secondary brachial plexus injury [78].

\section{Identification, Prevention and Treatment}

A thorough clinical exam is essential to identify poststroke shoulder pain. Patients' self-report of pain far underestimates the extent of pain found on physical exam: In one study, nearly $40 \%$ of post-stroke patients who denied shoulder pain would subsequently show pain on physical examination, even in those without evidence of visual or somatosensory neglect [71]. The most common physical signs of post-stroke shoulder pain were bicipital tendon tenderness, supraspinatus tenderness, and a positive Neer sign (pain with placement of fully pronated arm in forced flexion) [71].

Prevention is key to the management of post-stroke shoulder pain [79] (table 5). After the onset of severe upper extremity motor weakness, and prior to the development of spasticity, the shoulder has significant laxity and thus is particularly vulnerable to injury. Attention to stabilization during this flaccid stage, as well as a physiotherapy regimen that starts with passive range of motion, should commence as soon as the patient is medically stable [80].

Once the full pain syndrome has developed, treatment should commence. Subluxation rarely resolves spontaneously [81]. Treatment options include mechanical stabilization with shoulder slings, lap boards and arm troughs in wheelchairs, and shoulder strapping. Medications should be started conservatively, with simple analgesics and non-steroidal anti-inflammatories being used first line [79]. Anti-spasmodic agents may also be helpful if hypertonicity is contributing to pain; they can be used in conjunction with the physiotherapy regimen [74].

Transcutaneous neuromuscular electrical stimulation (TENS) is a treatment option. TENS is proposed to be effective through the gate-control theory of pain, activating myelinated sensory fibers and disrupting the pain signals of unmyelinated C-fibers [82]. Functional electrical stimulation (FES) may be used to maintain isometric electrical strength of the shoulder girdle, and has been shown to improve pain, range of motion, and arm function [76]. FES has been targeted at the supraspinatus and posterior deltoid muscles, as these are critical for maintaining shoulder stability [83]. Botulinum toxin injections have been associated with improvement, and in some cases resolu- 
Fig. 2. Shoulder anatomy (lateral view). Diagram adapted from Netter's anatomy and amicus visual solutions.

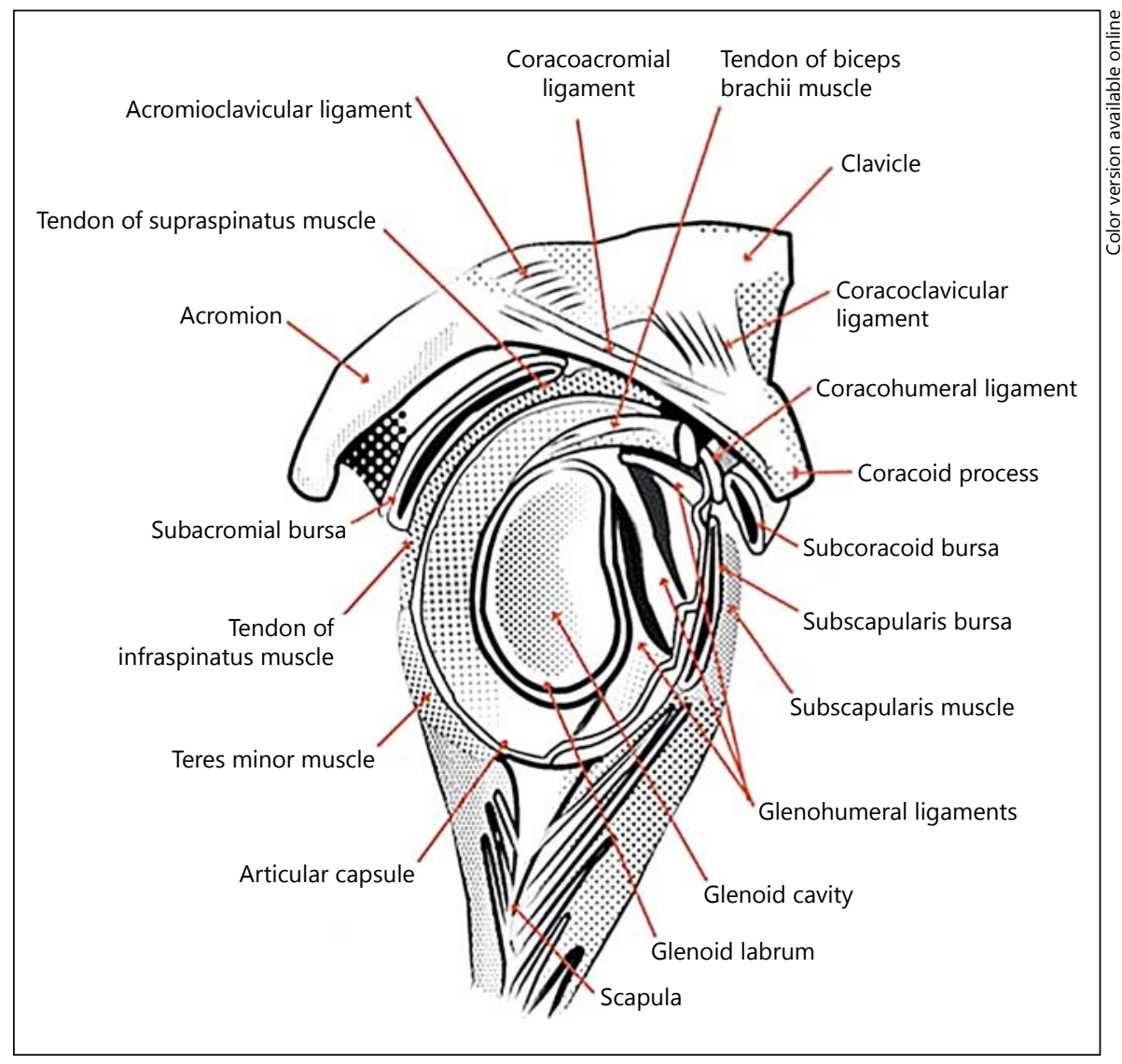

Table 5. Prevention of hemiplegic shoulder pain [91]

1 Joint protection strategies

Positioning and supporting the arm during rest

Protecting and supporting the arm during functional mobility

Protecting and supporting the arm during wheelchair use by using a hemi-tray or arm trough

During the flaccid stage slings can be used to prevent injury, however beyond the flaccid stage the use of slings remains controversial

2 Overhead pulleys should not be used

3 The arm should not be moved beyond 90 degrees of shoulder flexion or abduction, unless the scapula is upwardly rotated and the humerus is laterally rotated

4 Patients and staff should be educated to correctly handle the involved arm

tion, of shoulder pain [84]. Surgery is also an option for refractory cases, with operations on contractures in muscle tendons, surgical repair of rotation cuff tears, and scapular mobilization.

A contracture is a permanent shortening of a muscle or joint, usually in response to prolonged hypertonic spasticity in a concentrated muscle area. In one registry, contractures were found in half of patients at 6 months post-stroke [85]. The commonest sites for contractures were the hip, shoulder, and elbow [86]. Shoulder contractures were most common in those with the most severe disability [86]. 
Therapies for contractures remain controversial. Regular stretch therapy has not been shown to have a long-term impact on joint mobility, pain, or quality of life [87]. Surface neuromuscular electrical stimulation may reduce the progression of contractures in elderly stroke patients, quantified by a change in the passive range of motion [88].

\section{Complex Regional Pain Syndrome}

Prevalence, Risk Factors and Clinical Characteristics

Complex regional pain syndrome (CRPS) involves pain, edema, vasomotor changes, and patchy bone demineralization of an extremity. It is also referred to as reflex sympathetic dystrophy, causalgia, and Sudeck's atrophy; or shoulder-hand syndrome when seen after stroke. There are two types: Type I, where there is no definable nerve lesion, and Type II, where a definable nerve lesion is present. Most stroke patients are categorized as Type I CRPS, although it is impossible to rule out microtrauma to nerves [89].

The reported incidence of CRPS after stroke is variable, with estimates between 2 and 49\% [90, 91]. This variation is at least in part due to the lack of consensus on diagnostic criteria in previous studies. In an effort to standardize the diagnosis of CRPS, the International Association for the Study of Pain (IASP) have adopted a set of clinical diagnostic criteria, classifying both sensory and sudomotor/vasomotor components [92, 93].

\section{Proposed Pathophysiology}

Impaired biomechanics of the glenohumeral joint have been implicated in the development of CRPS after stroke. This is supported by findings that subluxation is more common in these patients [94] and that the degree of weakness and immobility in the shoulder is related to the probability of developing CRPS [95]. It is postulated that trauma to the affected shoulder is associated with the development of CRPS [96]; however, how this translates into the constellation of symptoms associated with this particular pain syndrome is not known. Historically, hyperactivity of the sympathetic nervous system and changes in the peripheral nervous system were implicated; contemporary imaging studies also demonstrate the role of the central nervous system and local inflammation in this process. Alterations in thalamic perfusion have been found in CRPS patients [97]. These patients also display cortical sensory abnormalities [98]. Local inflammation of the affected extremity has been demonstrated by increased migration of immunoglobulins and other inflammatory mediators toward the area affected by CRPS [ 99 , 100]. Relative hypoxia has been demonstrated in the af- fected limb, with evidence of reduced capillary oxygenation when employing skin spectrophotometry [101] and local muscle acidosis on nuclear magnetic resonance spectroscopy [102].

Identification in the Clinical Setting, Prevention and Treatment

The clinical findings of CRPS are outlined in the diagnostic criteria provided by the IASP [19]. These include a constellation of symptoms and signs including neuropathic pain, motor limitations, vasomotor and sudomotor changes, and trophic changes affecting hair, nails, and skin in the affected limb. Plain films or CT of affected areas often demonstrate patchy bone loss in late CPRS $[103,104]$. MRI of the affected area may demonstrate skin thickening, tissue enhancement with contrast material, and soft tissue edema to support a diagnosis of CRPS [105].

CRPS treatments target the proposed causative mechanisms. There is no definitive treatment for post-stroke CRPS at this time. Goals of treatment are to reduce pain, maintain joint mobility, and restore function [106]. An interdisciplinary approach involving occupational and physical therapists to provide mobilization and strengthening of the affected limb, edema control, and desensitization techniques is considered a cornerstone of care in these patients [106].

Given that early joint injury can contribute to the development of CRPS, a preventative approach to joint injury may also reduce incidence [107]. To target sympathetic mediated effects, nerve blocks can be given at the level of the stellate ganglion [108]. Desensitization is a gradual process in which increasingly painful sensory stimulus is applied to the affected area. It is thought that this gradual increase in normalized sensation may reset the altered central processing in the nervous system [109]. Other non-pharmacological therapies such as motor imagery and mirror therapy have been studied in the treatment of CRPS. With mirror therapy, participants watch their unaffected limb in the mirror as though it is the affected limb, and perceive it moving with ease. Mirror therapy is associated with decreased CRPS-related pain and improved motor recovery after stroke [110]. Proposed mechanisms include cortical change and reorganization. Psychological factors, such as depression and anxiety, may be premorbid or occur in response to pain; addressing these components is an important part of managing the disorder $[111,112]$.

Pharmacologic agents used for neuropathic pain, including memantine [113], gabapentin [114], carbamazepine [115], and heterocyclic antidepressants [116] have all 
had suggested benefit in CRPS, though their efficacy has not been directly studied in the stroke population. Bisphosphonates, which are thought to counteract osteoclast hyperactivity, have demonstrated pain reduction in CRPS in a non-stroke cohort [117]. As inflammation likely plays a role in the pathogenesis and continuance of CRPS, it is also a potential therapeutic target. Corticosteroids have been tested in non-stroke and post-stroke CRPS populations $[116,118]$. Data from two small randomized placebo-controlled trials in post-traumatic [119] and poststroke [120] CRPS demonstrate significant pain relief with a short course of oral glucocorticoids.

\section{Post Stroke Headache}

While common in our own clinical experience, poststroke headache remains poorly characterized in the literature. Chronic headache has been estimated to occur in $10 \%$ of patients after stroke $[6,20]$.

Some features of chronic post-stroke headache disorder have been identified. Headache at stroke onset is shown to be predictive of headache at 6 months post-stroke [33]. Those with a history of tension-type or vascular headache are more likely to develop headache with or after stroke [121]. In general, post-stroke headache has been characterized as a tension-type headache that has a pressing quality, and is not aggravated by movement $[33,122]$.

The pathophysiology of post-stroke headache is not well understood. It has been proposed that the predominant underlying mechanism is stimulation of the trigem- inovascular system [21]. This may be due to various factors including brain injury, damage or alterations to the blood vessels, subsequent inflammation or disruption and/or reinnervation of pain pathways, or even medications (dipyridamole, for example, has been commonly associated with headache $[5,123])$. Further study is needed regarding the prevalence, risk factors, and therapy for this condition.

\section{Conclusion}

Pain is a common phenomenon in stroke patients. There are multiple contributing mechanisms for poststroke pain and several well-characterized, post-stroke pain syndromes. Nonetheless, the identification of pain in the post-stroke population often proves challenging. Careful inquiry, use of rating scales, and physical examination may lead to improved identification and effective treatment of post-stroke pain. This may improve patient comfort, mood, rehabilitation, and quality of life.

\section{Acknowledgment}

The authors would like to thank Mr. Franco Cermeno for the creation of the shoulder graphic.

\section{Conflicts of Interest}

None to declare.

\section{References}

1 Naess H, Lunde L, Brogger J: The effects of fatigue, pain, and depression on quality of life in ischemic stroke patients: the bergen stroke study. Vasc Health Risk Manag 2012;8:407-413.

2 Klit H, Finnerup NB, Andersen G, Jensen TS: Central poststroke pain: a population-based study. Pain 2011;152:818-824.

3 Langhorne P, Stott DJ, Robertson L, MacDonald J, Jones L, McAlpine C, et al: Medical complications after stroke: a multicenter study. Stroke 2000;31:1223-1229.

4 Widar M, Samuelsson L, Karlsson-tivenius S, Ahlstrom G: Long-term pain conditions after a stroke. J Rehabil Med 2002;34:165-170.

5 O’Donnell MJ, Diener HC, Sacco RL, Panju AA, Vinisko R, Yusuf S: Chronic pain syndromes after ischemic stroke: PRoFESS trial. Stroke 2013;44:1238-1243.

6 Hoang CL, Salle JY, Mandigout S, Hamonet J, Macian-Montoro F, Daviet JC: Physical fac- tors associated with fatigue after stroke: an exploratory study. Top Stroke Rehabil 2012;19: 369-376.

7 Lundström E, Smits A, Terént A, Borg J: Risk factors for stroke-related pain 1 year after firstever stroke. Eur J Neurol 2009;16:188-193.

8 Tang WK, Liang H, Mok V, Ungvari GS, Wong KS: Is pain associated with suicidality in stroke? Arch Phys Med Rehabil 2013;94:863-866.

9 Jonsson AC, Lindgren I, Hallstrom B, Norrving B, Lindgren A: Prevalence and intensity of pain after stroke: a population based study focusing on patients' perspectives. J Neurol Neurosurg Psychiatry 2006;77:590-595.

10 Moriarty O, McGuire BE, Finn DP: The effect of pain on cognitive function: a review of clinical and preclinical research. Prog Neurobiol 2011;93:385-404

11 Okada K, Murase K, Kawakita K: Effects of electrical stimulation of thalamic nucleus submedius and periaqueductal gray on the visceral nociceptive responses of spinal dorsal horn neurons in the rat. Brain Res 1999;834: 112-121.

12 Bair MJ, Robinson RL, Katon W, Kroenke K Depression and pain comorbidity: a literature review. Arch Intern Med 2014;163:2433-2445.

13 Park DC, Glass JM, Minear M, Crofford LJ: Cognitive function in fibromyalgia patients. Arthritis Rheum 2001;44:2125-2133.

$14 \mathrm{Hu}$ Y, Yang J, Hu Y, Wang Y, Li W: Amitriptyline rather than lornoxicam ameliorates neuropathic pain-induced deficits in abilities of spatial learning and memory. Eur J Anaesthesiol 2010;27:162-168.

15 Jamison RN, Schein JR, Vallow S, Ascher S, Vorsanger GJ, Katz NP: Neuropsychological effects of long-term opioid use in chronic pain patients. J Pain Symptom Manage 2003;26: 913-921. 
16 Ehrich EW, Bolognese JA, Watson DJ, Kong SX: Effect of rofecoxib therapy on measures of health-related quality of life in patients with osteoarthritis. Am J Manag Care 2001;7:609616

17 Rowbotham M, Harden N, Stacey B, Bernstein P, Magnus-Miller L: Gabapentin for the treatment of postherpetic neuralgia: a randomized controlled trial. JAMA 1998;280: 1837-1842.

18 Katz N: The impact of pain management on quality of life. J Pain Symptom Manage 2002; 24(1 suppl):S38-S47.

19 McCarberg BH, Barkin RL: Long-acting opioids for chronic pain: pharmacotherapeutic opportunities to enhance compliance, quality of life, and analgesia. Am J Ther 2001;8:181186.

20 Bowsher D: The management of central poststroke pain. Postgrad Med J 1995;71:598-604.

21 Sommerfeld DK, Welmer AK: Pain following stroke, initially and at 3 and 18 months after stroke, and its association with other disabilities. Eur J Neurol 2012;19:1325-1330.

22 Weiner DK, Rudy TE: Attitudinal barriers to effective treatment of persistent pain in nursing home residents. J Am Geriatr Soc 2002;50: 2035-2040.

23 Catananti C, Gambassi G: Pain assessment in the elderly. Surg Oncol 2010;19:140-148.

24 Smith JH, Bottemiller KL, Flemming KD, Michael Cutrer F, Strand EA: Inability to selfreport pain after a stroke: a population-based study. Pain 2013;154:1281-1286.

25 Price CI, Curless RH, Rodgers H: Can stroke patients use visual analogue scales? Stroke 1999;30:1357-1361.

26 Benaim C, Froger J, Cazottes C, Gueben D, Porte M, Desnuelle C, et al: Use of the faces pain scale by left and right hemispheric stroke patients. Pain 2007;128:52-58.

27 Pain terms: a current list with definitions and notes on usage. Recommended by the IASP Subcommittee on Taxonomy. Pain 1979; 6:S215-S221

28 Andersen G, Vestergaard K, IngemanNielsen M, Jensen TS: Incidence of central post-stroke pain. Pain 1995;61:187-193.

29 Kumar G, Soni CR: Central post-stroke pain: current evidence. J Neurol Sci 2009;284:10-17.

30 Hansson P: Post-stroke pain case study: clinical characteristics, therapeutic options and long-term follow-up. Eur J Neurol 2004; 11(suppl 1):22-30.

31 Klit H, Finnerup NB, Jensen TS: Central poststroke pain: clinical characteristics, pathophysiology, and management. Lancet Neurol 2009;8:857-868.

32 Acerra NE, Souvlis T, Moseley GL: Stroke, complex regional pain syndrome and phantom limb pain: can commonalities direct future management? J Rehabil Med 2007;39: 109-114.

33 Hansen AP, Marcussen NS, Klit H, Andersen G, Finnerup NB, Jensen TS: Pain following stroke: a prospective study. Eur J Pain 2012; 16:1128-1136.
34 Canavero S, Bonicalzi V: Central Pain of Brain Origin: Epidemiology and Clinical Features. Cambridge University Press, 2007, pp 9-99.

35 Leijon G, Boivie J, Johansson I: Central poststroke pain - neurological symptoms and pain characteristics. Pain 1989;36:13-25.

36 Harno H, Haapaniemi E, Putaala J, Haanpaa M, Makela JP, Kalso E, et al: Central poststroke pain in young ischemic stroke survivors in the Helsinki young stroke registry. Neurology 2014;83:1147-1154.

37 Tasker RR: Microelectrode findings in the thalamus in chronic pain and other conditions. Stereotact Funct Neurosurg 2001;77: 166-168.

38 Nasreddine ZS, Saver JL: Pain after thalamic stroke: right diencephalic predominance and clinical features in 180 patients. Neurology 1997;48:1196-1199.

39 Bassetti C, Bogousslavsky J, Regli F: Sensory syndromes in parietal stroke. Neurology 1993;43:1942-1949.

40 Merskey H, Watson GD: The lateralisation of pain. Pain 1979;7:271-280.

41 Hall W, Clark IM: Pain and laterality in a British pain clinic sample. Pain 1982;14:63-66.

42 Benavente OR, Pearce LA, Bazan C, Roldan AM, Catanese L, Bhat Livezey VM, et al: Clinical-MRI correlations in a multiethnic cohort with recent lacunar stroke: the SPS3 trial. Int J Stroke 2014;9:1057-1064.

43 Attal N, Gaude V, Brasseur L, Dupuy M, Guirimand F, Parker F, et al: Intravenous lidocaine in central pain: a double-blind, placebo-controlled, psychophysical study. Neurology 2000;54:564-574.

44 Vick PG, Lamer TJ: Treatment of central post-stroke pain with oral ketamine. Pain 2001;92:311-313.

45 Lampl C, Yazdi K, Roper C: Amitriptyline in the prophylaxis of central poststroke pain. Preliminary results of 39 patients in a placebo-controlled, long-term study. Stroke 2002; 33:3030-3032.

46 Pellicane AJ, Millis SR: Efficacy of methylprednisolone versus other pharmacologic interventions for the treatment of central poststroke pain: a retrospective analysis. J Pain Res 2013;6:557-563.

47 Cruccu G, Aziz TZ, Garcia-Larrea L, Hansson $P$, Jensen TS, Lefaucheur JP, et al: EFNS guidelines on neurostimulation therapy for neuropathic pain. Eur J Neurol 2007;14:952970.

48 Nguyen JP, Lefaucheur JP, Decq P, Uchiyama $\mathrm{T}$, Carpentier A, Fontaine D, et al: Chronic motor cortex stimulation in the treatment of central and neuropathic pain. Correlations between clinical, electrophysiological and anatomical data. Pain 1999;82:245-251.

49 Rasche D, Rinaldi PC, Young RF, Tronnier VM: Deep brain stimulation for the treatment of various chronic pain syndromes. Neurosurg Focus 2006;21:E8.

50 Khedr EM, Kotb H, Kamel NF, Ahmed MA, Sadek R, Rothwell JC: Longlasting antalgic effects of daily sessions of repetitive transcra- nial magnetic stimulation in central and peripheral neuropathic pain. J Neurol Neurosurg Psychiatry 2005;76:833-838.

51 McGeoch PD, Williams LE, Lee RR, Ramachandran VS: Behavioural evidence for vestibular stimulation as a treatment for central poststroke pain. J Neurol Neurosurg Psychiatry 2008;79:1298-1301.

52 Malhotra S, Pandyan AD, Day CR, Jones PW, Hermens H: Spasticity, an impairment that is poorly defined and poorly measured. Clin Rehabil 2009;23:651-658.

53 Wissel J, Schelosky LD, Scott J, Christe W, Faiss JH, Mueller J: Early development of spasticity following stroke: a prospective, observational trial. J Neurol 2010;257:10671072.

54 Sheean DG: Is spasticity painful? Eur J Neurol 2009;16:157-158.

55 Hosomi K, Saitoh Y, Kishima H, Oshino S, et al: Electrical stimulation of primary motor cortex within the central sulcus for intractable neuropathic pain. Clin Neurophysiol 2008; 119:993-1001.

56 Dietz V, Sinkjaer T: Spastic movement disorder: impaired reflex function and altered muscle mechanics. Lancet Neurol 2007;6: 725-733

57 Truini A, Barbanti P, Pozzilli C, Cruccu G: A mechanism-based classification of pain in multiple sclerosis. J Neurol 2013;260:351367.

58 Leathley MJ, Gregson JM, Moore AP, Smith TL, Sharma AK, Watkins CL: Predicting spasticity after stroke in those surviving to 12 months. Clin Rehabil 2004;18:438-443.

59 Wood DE, Burridge JH, van Wijck FM, McFadden C, Hitchcock RA, Pandyan AD, et al: Biomechanical approaches applied to the lower and upper limb for the measurement of spasticity: a systematic review of the literature. Disabil Rehabil 2005;27:19-32

60 Demetrios M, Khan F, Turner-Stokes L, Brand C, McSweeney S: Multidisciplinary rehabilitation following botulinum toxin and other focal intramuscular treatment for poststroke spasticity. Cochrane Database Syst Rev 2013;6:CD009689.

61 Baker JA, Pereira G: The efficacy of botulinum toxin A for spasticity and pain in adults: a systematic review and meta-analysis using the grades of recommendation, assessment, development and evaluation approach. Clin Rehabil 2013;27:1084-1096.

62 Bakheit AM: The pharmacological management of post-stroke muscle spasticity. Drugs Aging 2012;29:941-947.

63 Gold R, Oreja-Guevara C: Advances in the management of multiple sclerosis spasticity: multiple sclerosis spasticity guidelines. Expert Rev Neurother 2013;13:55-59.

64 Graham LA: Management of spasticity revisited. Age Ageing 2013;42:435-441.

65 Sunnerhagen KS, Olver J, Francisco GE: Assessing and treating functional impairment in poststroke spasticity. Neurology 2013;80(3 suppl 2):S35-S44. 
66 Thibaut A, Chatelle C, Ziegler E, Bruno MA, Laureys S, Gosseries O: Spasticity after stroke: physiology, assessment and treatment. Brain Inj 2013;27:1093-1105.

67 Gamble GE, Barberan E, Bowsher D, Tyrrell PJ, Jones AK: Post stroke shoulder pain: more common than previously realized. Eur J Pain 2000;4:313-315.

68 Roy CW, Sands MR, Hill LD: Shoulder pain in acutely admitted hemiplegics. Clin Rehabil 1994;8:334-340.

69 Gamble GE, Barberan E, Laasch HU, Bowsher D, Tyrrell PJ, Jones AK: Poststroke shoulder pain: a prospective study of the association and risk factors in 152 patients from a consecutive cohort of 205 patients presenting with stroke. Eur J Pain 2002;6: 467-474.

70 Dromerick A, Reding M: Medical and neurological complications during inpatient stroke rehabilitation. Stroke 1994;25:358-361.

71 Dromerick AW, Edwards DF, Kumar A: Hemiplegic shoulder pain syndrome: frequency and characteristics during inpatient stroke rehabilitation. Arch Phys Med Rehabil 2008;89:1589-1593.

72 Lindgren I, Jönsson AC, Norrving B, Lindgren A: Shoulder pain after stroke: a prospective population-based study. Stroke 2007;38: 343-348.

73 Rajaratnam BS, Venketasubramanian N, Kumar PV, Goh JC, Chan YH: Predictability of simple clinical tests to identify shoulder pain after stroke. Arch Phys Med Rehabil 2007;88: 1016-1021.

74 Van Ouwenaller C, Laplace PM, Chantraine A: Painful shoulder in hemiplegia. Arch Phys Med Rehabil 1986;67:23-26.

75 Poulin de Courval L, Barsauskas A, Berenbaum B, Dehaut F, Dussault R, Fontaine FS, et al: Painful shoulder in the hemiplegic and unilateral neglect. Arch Phys Med Rehabil 1990;71:673-676.

76 Faghri PD, Rodgers MM, Glaser RM, Bors JG, Ho C, Akuthota P: The effects of functional electrical stimulation on shoulder subluxation, arm function recovery, and shoulder pain in hemiplegic stroke patients. Arch Phys Med Rehabil 1994;75:73-79.

77 Paci M, Nannetti L, Taiti P, et al: Shoulder subluxation after stroke: relationships with pain and motor recovery. Physiother Res Int 2007;12:95-104.

78 Chino N: Electrophysiological investigation on shoulder subluxation in hemiplegics. Scand J Rehabil Med 1981;13:17-21.

79 Dawson AS, Knox J, McClure A, Foley N, Teasell R; Stroke Rehabilitation Best Practices Writing Group: Management of shoulder pain following stroke; in Lindsay MP, Gubitz G, Bayley M, Phillips S (eds): Canadian Best Practice Recommendations for Stroke Care. Ottawa, Ontario, Canada, Heart and Stroke Foundation and the Canadian Stroke Network, 2013, pp 47-50.

80 Vasudevan JM, Browne BJ: Hemiplegic shoulder pain: an approach to diagnosis and management. Phys Med Rehabil Clin N Am 2014;25:411-437.

81 Zorowitz RD: Recovery patterns of shoulder subluxation after stroke: a six-month followup study. Top Stroke Rehabil 2001;8:1-9.

82 Garrison DW, Foreman RD: Decreased activity of spontaneous and noxiously evoked dorsal horn cells during transcutaneous electrical nerve stimulation (TENS). Pain 1994;58:309315.

83 Linn SL, Granat MH, Lees KR: Prevention of shoulder subluxation after stroke with electrical stimulation. Stroke 1999;30:963-968.

84 Bhakta BB, Cozens JA, Bamford JM, Chamberlain MA: Use of botulinum toxin in stroke patients with severe upper limb spasticity. J Neurol Neurosurg Psychiatry 1996;61:30-35.

85 Sackley C, Brittle N, Patel S, Ellins J, Scott M, Wright $\mathrm{C}$, et al: The prevalence of joint contractures, pressure sores, painful shoulder, other pain, falls, and depression in the year after a severely disabling stroke. Stroke 2008 ; 39:3329-3334.

86 Kwah LK, Harvey LA, Diong JH, Herbert RD: Half of the adults who present to hospital with stroke develop at least one contracture within six months: an observational study. J Physiother 2012;58:41-47.

87 Katalinic OM, Harvey LA, Herbert RD: Effectiveness of stretch for the treatment and prevention of contractures in people with neurological conditions: a systematic review. Phys Ther 2014;91:11-24.

88 Malhotra S, Rosewilliam S, Hermens H, Roffe C, Jones P, Pandyan AD: A randomized controlled trial of surface neuromuscular electrical stimulation applied early after acute stroke: effects on wrist pain, spasticity and contractures. Clin Rehabil 2013;27:579-590.

89 Yu DT: Shoulder pain and other musculoskeletal complications; in Stein J, Harvey RL, Macko RF, Winstein CJ, Zorowitz RD (eds): Stroke Recovery and Rehabilitation. New York, DemosMedical, 2009, pp 437-451.

90 McLean DE: Medical complications experienced by a cohort of stroke survivors during inpatient, tertiary-level stroke rehabilitation. Arch Phys Med Rehabil 2004;85:466-469.

91 Kocabas H, Levendoglu F, Ozerbil OM, Yuruten B: Complex regional pain syndrome in stroke patients. Int J Rehabil Res 2007;30: 33-38.

92 Harden RN, Bruehl S, Galer BS, Saltz S, Bertram M, Backonja $\mathrm{M}$, et al: Complex regional pain syndrome: are the IASP diagnostic criteria valid and sufficiently comprehensive? Pain 1999;83:211-219.

93 Harden RN, Bruehl SP: Complex Regional Pain Syndrome: Treatment Guidelines. Milford, CT, RSDSA Press, 2006.

94 Dursun E, Dursun N, Ural CE, Cakci A: Glenohumeral joint subluxation and reflex sympathetic dystrophy in hemiplegic patients. Arch Phys Med Rehabil 2000;81:944-946.

95 Gokkaya NK, Aras M, Yesiltepe E, Koseoglu F: Reflex sympathetic dystrophy in hemiplegia. Int J Rehabil Res 2006;29:275-279.
96 Chae J: Poststroke complex regional pain syndrome. Top Stroke Rehabil 2010;17:151162.

97 Fukumoto M, Ushida T, Zinchuk VS, Yamamoto H, Yoshida S: Contralateral thalamic perfusion in patients with reflex sympathetic dystrophy syndrome. Lancet 1999;354: 1790-1791.

98 Juottonen $\mathrm{K}$, Gockel $\mathrm{M}$, Silén T, Hurri $\mathrm{H}$, Hari R, Forss N: Altered central sensorimotor processing in patients with complex regional pain syndrome. Pain 2002;98:315323.

99 Schinkel C, Gaertner A, Zaspel J, Zedler S, Faist E, Schuermann M: Inflammatory mediators are altered in the acute phase of posttraumatic complex regional pain syndrome. Clin J Pain 2006;22:235-239.

100 Okudan B, Celik C: Determination of inflammation of reflex sympathetic dystrophy at early stages with Tc-99m HIG scintigraphy: preliminary results. Rheumatol Int 2006;26:404-408

101 Koban M, Leis S, Schultze-Mosgau S, Birklein F: Tissue hypoxia in complex regional pain syndrome. Pain 2003;104:149157.

102 Heerschap A, den Hollander JA, Reynen H, Goris RJ: Metabolic changes in reflex sympathetic dystrophy: a 31P NMR spectroscopy study. Muscle Nerve 1993;16:367373.

103 Kozin F, Genant HK, Bekerman C, McCarty DJ: The reflex sympathetic dystrophy syndrome. II. Roentgenographic and scintigraphic evidence of bilaterality and of periarticular accentuation. Am J Med 1976;60: 332-338.

104 Sambrook P, Champion GD: Reflex sympathetic dystrophy; characteristic changes in bone on CT scan. J Rheumatol 1990;17: 1425-1426.

105 Schweitzer ME, Mandel S, Schwartzman RJ, Knobler RL, Tahmoush AJ: Reflex sympathetic dystrophy revisited: MR imaging findings before and after infusion of contrast material. Radiology 1995;195:211-214.

106 Pertoldi S, Di Benedetto P: Shoulder-hand syndrome after stroke. A complex regional pain syndrome. Eura Medicophys 2005;41: 283-292.

107 Kondo I, Hosokawa K, Soma M, Iwata M, Maltais D: Protocol to prevent shoulderhand syndrome after stroke. Arch Phys Med Rehabil 2001;82:1619-1623.

108 Wasner G, Schattschneider J, Binder A, Baron R: Complex regional pain syndrome - diagnostic, mechanisms, CNS involvement and therapy. Spinal Cord 2003;41:61-75.

109 Harden RN: Complex regional pain syndrome. Br J Anaesth 2001;87:99-106.

110 Altschuler EL, Wisdom SB, Stone L, Foster C, Galasko D, Llewellyn DME, et al: Rehabilitation of hemiparesis after stroke with a mirror: early recanalisation in acute ischaemic stroke saves tissue at risk defined by MRI. Lancet 1999;353:2036-2037. 
111 Gierthmuhlen J, Binder A, Baron R: Mechanism-based treatment in complex regional pain syndromes. Nat Rev Neurol 2014;10: 518-528.

112 Lohnberg JA, Altmaier EM: A review of psychosocial factors in complex regional pain syndrome. J Clin Psychol Med Settings 2013; 20:247-254.

113 Sinis N, Birbaumer N, Gustin S, Schwarz A, Bredanger S, Becker ST, et al: Memantine treatment of complex regional pain syndrome: a preliminary report of six cases. Clin J Pain 2007;23:237-243.

114 van de Vusse AC, Stomp-van den Berg SG, Kessels AH, Weber WE: Randomised controlled trial of gabapentin in complex regional pain syndrome type 1 [ISRCTN84121379]. BMC Neurol 2004;4:13.
115 Harke H, Gretenkort P, Ladleif HU, Harke $\mathrm{O}$ : The response of neuropathic pain and pain in complex regional pain syndrome I to carbamazepine and sustained-release morphine in patients pretreated with spinal cord stimulation: a double-blinded randomized study. Anesth Analg 2001;92:488-495.

116 Kingery WS: A critical review of controlled clinical trials for peripheral neuropathic pain and complex regional pain syndromes. Pain 1997;73:123-139.

117 Robinson JN, Sandom J, Chapman PT: Efficacy of pamidronate in complex regional pain syndrome type I. Pain Med 2004;5:276280.

118 Kalita J, Vajpayee A, Misra UK: Comparison of prednisolone with piroxicam in complex regional pain syndrome following stroke: a randomized controlled trial. QJM 2006;99: 89-95.
119 Christensen K, Jensen EM, Noer I: The reflex dystrophy syndrome response to treatment with systemic corticosteroids. Acta Chir Scand 1982;148:653-655.

120 Braus DF, Krauss JK, Strobel J: The shoulderhand syndrome after stroke: a prospective clinical trial. Ann Neurol 1994;36:728-733.

121 Arboix A, Massons J, Oliveres M, Arribas MP, Titus F: Headache in acute cerebrovascular disease: a prospective clinical study in 240 patients. Cephalalgia 1994;14:37-40.

122 Widar M, Ahlström G, Ek AC: Health-related quality of life in persons with long-term pain after a stroke. J Clin Nurs 2004;13:497505.

123 Diener HC, Cunha L, Forbes C, Sivenius J, Smets P, Lowenthal A: European stroke prevention study. 2. Dipyridamole and acetylsalicylic acid in the secondary prevention of stroke. J Neurol Sci 1996;143:1-13. 